\title{
SIMPLIFIED ESTIMATION OF SEISMIC LIFE-CYCLE COSTS
}

\author{
James L. Beck, M.ASCE, Keith A. Porter, M.ASCE, and Rustem V. Shaikhutdinov
}

Keywords: probable maximum loss, probable frequent loss, expected annualized loss, loss estimation, seismic risk, seismic life-cycle costs

\begin{abstract}
Most seismic risk assessments for economic decision-making of commercial buildings are based on a risk metric called probable maximum loss $(P M L)$ that is associated with losses from an earthquake shaking severity with a 500year return period. For various reasons, $P M L$ is a poor metric for economic performance assessment. This paper introduces an analogous measure, the probable frequent loss $(P F L)$, defined as the mean loss resulting from shaking with $10 \%$ exceedance probability in 5 years (an approximately 50 -year event). It overcomes many of the problems of $P M L$, and offers the advantage that expected seismic lifecycle costs and expected annualized loss are approximately proportional to $P F L$ through a seismic hazard coefficient that depends on site characteristics, fundamental period, and damage shaking threshold, and can be tabulated for ready use. A brief review is given of a building-specific seismic vulnerability method that may be used to calculate $P F L$.
\end{abstract}

\section{INTRODUCTION: RISK IN REAL-ESTATE INVESTMENT DECISIONS}

A recent study of the effects of seismic risk on lifetime property value found that for a sample commercial building in Van Nuys, California, lifetime seismic repair costs were dominated by frequent, moderate levels of shaking (Beck et al., 2002). This is interesting because economic risk information for this and most other commercial buildings in California is limited to probable maximum loss (PML), a loss level typically associated with large, rare events that recur on average every 500 years or so (see Zadeh, 2000, and ASTM, 1999, for discussions of PML). Interviews with commercial developers and investors indicate that PML is of little use to these property stakeholders. It is standard practice in California for a lender to require a commercial property buyer to show that the $P M L$ for the property is lower than some threshold value in order to secure a commercial mortgage without earthquake insurance. However, buyers cannot employ $P M L$ as an expense in their financial analysis based on the present value of future net operating income, and they also tend to consider the 500-year loss irrelevant to their much-shorter planning period.

It might be valuable to develop a scenario loss parameter similar to $P M L$ but that reflects a shorter planning period and allows for estimation of expected annualized loss $(E A L)$ and expected seismic life-cycle costs, $E[L]$. The latter represents the

(JLB) Professor, California Institute of Technology, 1200 E California Blvd MC 104-44, Pasadena, CA 91125-4400 (KAP) Senior Research Fellow, California Institute of Technology, 1200 E California Blvd MC 104-44, Pasadena, CA 91125-4400

(RVS) Graduate Research Assistant, California Institute of Technology, 1200 E California Blvd MC 104-44, Pasadena, CA $91125-4400$ 
present value of earthquake losses expected for a structure over some specified lifetime or planning period and so it can be used in a financial analysis as an operating expense. The calculation of seismic lifecycle costs allows a rational treatment of the economic risk to a structure from future earthquakes when making financial decisions about commercial property. A simplified method for its calculation could make economic seismic risk a market force in the commercial property market in seismically-active areas.

\section{CALCULATING SEISMIC LIFE-CYCLE COSTS}

We use a Poisson process as the probability model for the arrival of damaging earthquake events and assume that the severity of the ground shaking is independent between events, as is the consequent loss. It can be shown (Beck et al., 2002) that the expected present value of future earthquake losses over a time period $t$ is given by:

$$
E[L]=E A L \cdot\left(\frac{1-\exp (-r t)}{r}\right)
$$

where $r$ is the discount rate ("risk-free" real interest rate). Under these same conditions, expected annualized loss is given by:

$$
E A L=V \int_{S=0}^{\infty} y(S) g(S) d S
$$

where $V$ denotes value exposed to loss (e.g., replacement cost of the building), $S$ refers to the severity of earthquake shaking (e.g., spectral acceleration at the site), $y(S)$ is the mean seismic vulnerability function (average level of loss as a fraction of $V$ given the occurrence of an event of shaking severity $S$ ), and $g(S)$ is the mean hazard function (average annual frequency of experiencing severity $S$ per unit $S$ ).

Hazard information to establish $g(S)$ for a site is increasingly available; for example, the US Geological Survey provides such information at a website (http://eqint.cr.usgs.gov/eq/html/lookup.shtml) and encoded in software (Leyendecker, 2001). However, to determine $y(S)$ over its domain requires either large quantities of empirical data (which for various reasons do not exist in reliable form), or laborious engineering analyses that require a skillset beyond that of most engineers, or the exercise of expert opinion, such as that encoded in the software HAZUS (NIBS and FEMA, 1999) and ST-RISK (Risk Engineering, 2002).

One can approximate EAL as follows. Let $G(S)$ denote the average annual frequency of exceeding shaking severity $S$, where $S$ may be taken as the $5 \%$-damped elastic spectral acceleration. Let $G(S)$ be approximated by:

$$
\ln G(S)=-m S+b
$$

The parameters $m$ and $b$ can be determined by a log-linear fit to the site hazard function. Notice that $g(S)$ is the negative first derivative of $G(S)$ with respect to $S$ :

$$
g(S)=m e^{b} e^{-m S}
$$


Let the seismic vulnerability function $y(S)$ be approximated by

$$
\begin{aligned}
y(S) & =a\left(S-S_{N Z}\right) \text { for } S>S_{N Z}, \\
& =0 \text { otherwise }
\end{aligned}
$$

where $S_{N Z}$ is a threshold level of $S$ below which there is no loss. We define a convenient point on the vulnerability function with which to evaluate $a$. Let EBE denote the economic-basis earthquake event that produces a site shaking severity with $10 \%$ exceedance probability in 5 years. $E B E$ is analogous to the design-basis earthquake $(D B E)$ referred to by recent building codes. Let $S_{E B E}$ refer to the shaking severity for the EBE. Define the probable frequent loss (PFL) as the mean level of loss (in money terms) for the $E B E$. It will be convenient to shift $\mathrm{S}$ by an amount $S_{N Z}$ so let $x=S-S_{N Z}$, then:

$$
\begin{gathered}
g(x)=m e^{-m S_{N Z}+b} e^{-m x} \\
y(x)=\frac{1}{S_{E B E}-S_{N Z}} \cdot \frac{P F L}{V} x \text { for } x>0
\end{gathered}
$$

We get an approximation for the expected annualized loss by substituting Equations 6 and 7 into Equation 2:

$$
\begin{aligned}
E A L & =P F L \frac{\left(m e^{-m S_{N Z}+b}\right)}{\left(S_{E B E}-S_{N Z}\right)} \int_{0}^{\infty} x e^{-m x} d x \\
& =P F L \cdot \frac{\left(e^{-m S_{N Z}+b}\right)}{m\left(S_{E B E}-S_{N Z}\right)} \\
& =P F L \cdot \frac{G\left(S_{N Z}\right)}{m\left(S_{E B E}-S_{N Z}\right)} \\
& =P F L \cdot H
\end{aligned}
$$

Here, $H$ contains only site hazard variables so it can be mapped as a scalar value for a given fundamental period, soil condition, and $S_{N Z}$. Its units are $\mathrm{yr}^{-1}$. It is then simple to calculate the expected seismic life-cycle costs using this approximation for EAL in Equation 1.

\section{SAMPLE COMPARISONS OF EXACT AND APPROXIMATE EAL}

We examine the accuracy of approximation for EAL given in Equation 8 by using several example buildings. In Beck et al. (2002), we evaluated the seismic vulnerability function of a well-studied high-rise hotel building located in Van Nuys, California, as it existed prior to the 1994 Northridge Earthquake. It is a seven-story, nonductile reinforced-concrete moment-frame building built in 1966. The structure is regular: 8 bays totaling $45.7 \mathrm{~m}(150 \mathrm{ft})$ in the east-west direction, 3 bays totaling 18.6 
$\mathrm{m}(61 \mathrm{ft})$ in the north-south. Story heights are $4.11 \mathrm{~m}(13 \mathrm{ft} 6 \mathrm{in})$ at the ground story, $2.65 \mathrm{~m}(8 \mathrm{ft} 6.5 \mathrm{in})$ for stories 2 through 6 , and $2.64 \mathrm{~m}(8 \mathrm{ft} 6 \mathrm{in})$ for the $7^{\text {th }}$ story. Lateral resistance is provided primarily by the perimeter moment frame.

We used the assembly-based vulnerability (ABV) method to estimate repair costs at $S_{a}=0.1,0.2, \ldots 2.0 \mathrm{~g}$ where $S_{a}$ is the $5 \%$-damped elastic spectral acceleration. The ABV method, introduced in Beck et al. (1999) and detailed in Porter (2000) is summarized in Porter et al. (2001). Very briefly, it involves selection of suite of ground-motion time histories, creation of a stochastic structural model, performance of nonlinear time-history structural analyses to determine structural response, assessment of probabilistic damage via component fragility functions, and assessment of loss via probabilistic construction cost-estimation. We use Monte Carlo simulation to implement the methodology. ABV has proven to be a useful research tool. We have used it to evaluate seismic risk and benefits of seismic-risk mitigation for steelframe, concrete, and woodframe buildings and to explore major contributors to uncertainty of economic seismic risk (Beck et al., 2002; Porter et al., 2002a,b).
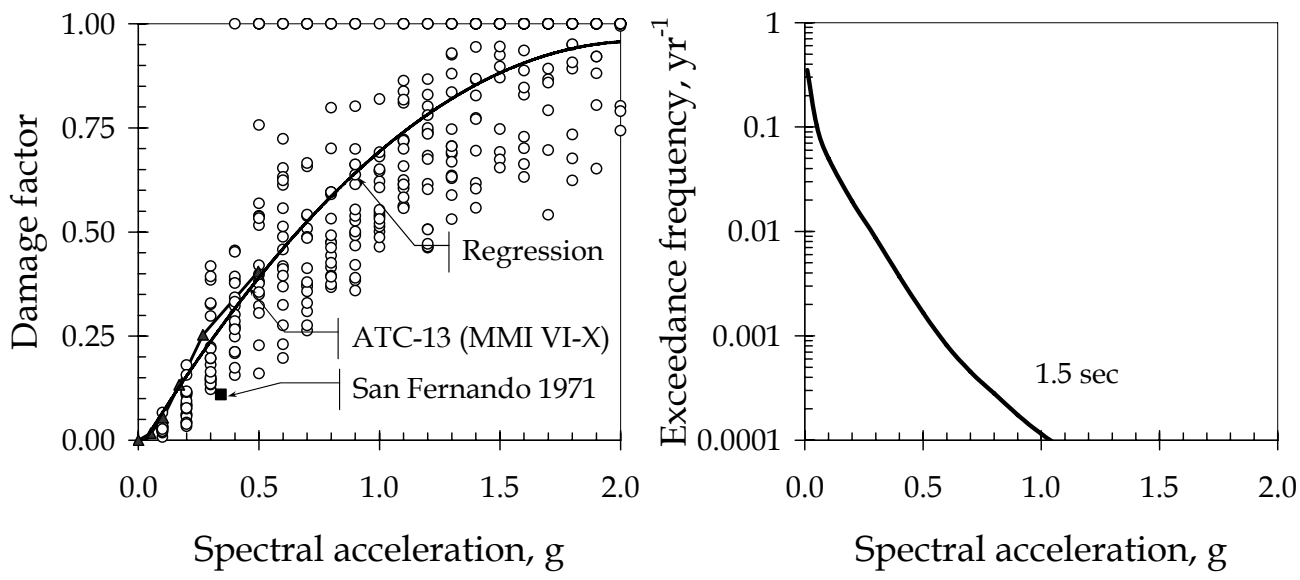

Figure 1. Seismic vulnerability (left) and site hazard function (right)

The analysis produced the seismic vulnerability function shown in the left diagram of Figure 1. The $x$-axis represents $S_{a}$ at the building's small-amplitude fundamental period, $1.5 \mathrm{sec}$. The $y$-axis measures repair cost as a fraction of replacement cost. Each dot represents one loss simulation: one nonlinear time-history structural analysis using one ground-motion time history, one simulation of the (uncertain) mass, damping, and force-deformation characteristics of the building, one simulation of the damage to each of 1233 structural and nonstructural components, and one simulation of the unit-repair cost for each of 17 combinations of component type and damage state. There are 20 simulations per each of $20 S_{a}$ levels. The 400 nonlinear time-history structural analyses took approximately 12 hours on an ordinary desktop computer; the subsequent loss analysis took less than an hour. The figure also shows for information purposes the loss the building experienced in the 1971 earthquake, and the seismic vulnerability function for nonductile concrete momentframe buildings from ATC-13 (1985). Figure 1 (right) provides the seismic hazard for the site in Van Nuys, California, calculated using Leyendecker's software (2001), 
and adjusted for NEHRP type-D soil using International Building Code adjustment factors (ICC, 2000). The total EAL, found by integrating Equation 2 numerically, is $\$ 54,600$.

Figure 2 (left) shows the incremental contribution to EAL from each level of $S_{a}$. The figure on the right expresses the cumulative total as a fraction of $\$ 54,600$, in terms of earthquake return period as opposed to $S_{a}$. The figures show that for this building in this highly seismic location, moderate, frequent earthquakes contribute the bulk of the risk. Half the expected annualized loss for this building results from shaking of $0.25 \mathrm{~g}$ or less, i.e., events with a return period of 50 years or less. Very little cumulative economic loss comes from large, rare events such as the $P M L$-level earthquake or larger (which at this site would have $S_{a} \approx 0.5 \mathrm{~g}$ ). We conclude from this that, as important as the 500 -year earthquake is as a design basis for life safety, it is largely irrelevant for economic considerations. Furthermore, at levels of shaking that contribute the bulk of the risk, the structure remains largely elastic. The ABV analysis indicates that at $S_{a}=0.1 \mathrm{~g}$, fewer than $5 \%$ of beams and columns experienced any damage. At $0.2 \mathrm{~g}$, approximately $10 \%$ of beams and columns are modeled as experiencing damage. At both levels, most of the structural damage is associated with cracking that is repairable through epoxy injection, and most of the total repair cost is associated with paint, glazing, and drywall. We conclude from this that, at the levels of shaking that contribute most significantly to economic loss, elastic structural analysis should reasonably estimate structural response.

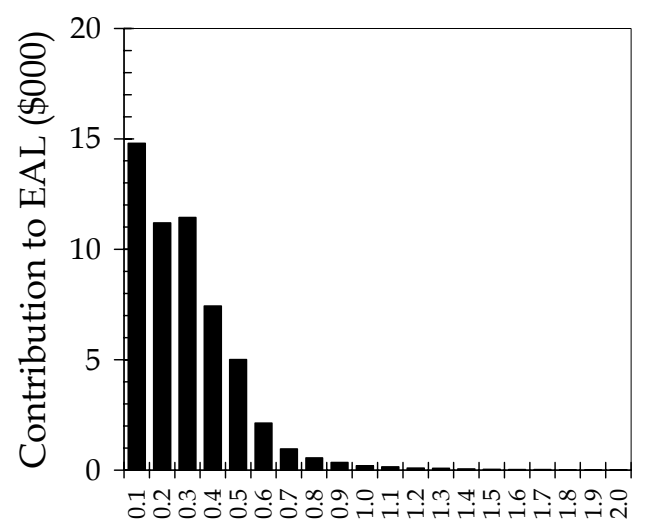

Spectral acceleration, $g$

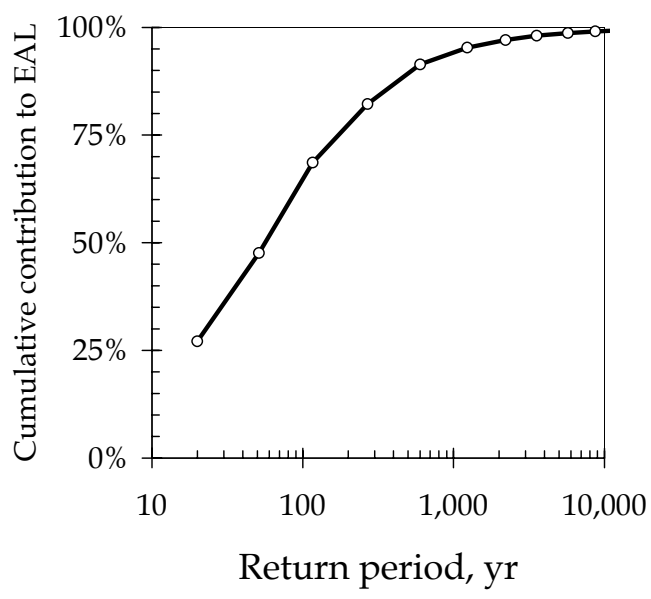

Figure 2. Incremental contribution to EAL (left) and cumulative contribution as percent (right)

To examine how well Equation 8 approximates EAL, a comparison is made in Table 1 of the exact value of $E A L$ calculated using Equation 2 with the approximation of Equation 8 for eight buildings: the Van Nuys hotel and seven woodframe buildings that were examined in the CUREE-Caltech Woodframe Project (Porter et al., 2002a). In this latter project, we performed $\mathrm{ABV}$ analyses of four hypothetical woodframe dwellings: a single-story, single-family dwelling ("small house"); a two-story singlefamily dwelling with attached garage ("large house"), a three-unit, two-story 
condominium building, and a 10-unit, three-story apartment building with tuck-under parking on the ground floor. Several variants of each woodframe building were considered: a poor-quality, typical-quality, and superior-quality version (defined primarily in terms of strength and stiffness of materials) and one or more seismic retrofit or redesign measures. The seven shown in Table 1 are the variants that have the characteristic that $S_{N Z}<S_{E B E}$, (which is required by Equation 5). In Table 1, "small, poor" and "small, typ" refer to the poor-quality and typical-quality variants of the small house. The remaining buildings refer to variants of the apartment building: poor quality ("apt poor"), typical quality ("apt typ"), superior quality (apt sup"), typical quality with the addition of a structural shearwall in the ground floor ("apt s/w"), and typical quality with the addition of structural steel frames in the ground floor garage opening ("apt s/f"). The woodframe dwellings are analyzed for an arbitrary site in Los Angeles, California, at $33.9^{\circ} \mathrm{N}, 118.2^{\circ} \mathrm{W}$. The hazard is calculated for $\mathrm{T}=0.2 \mathrm{sec}$, and adjusted for NEHRP soil category D.

Table 1. Approximation of expected annualized loss using probable frequent loss

\begin{tabular}{|c|c|c|c|c|c|c|c|c|}
\hline & Hotel & $\begin{array}{r}\text { Small, } \\
\text { poor }\end{array}$ & $\begin{array}{r}\text { Small, } \\
\text { typ }\end{array}$ & $\begin{array}{l}\text { Apt, } \\
\text { poor }\end{array}$ & $\begin{array}{r}\text { Apt, } \\
\text { typ }\end{array}$ & $\begin{array}{l}\text { Apt, } \\
\text { sup }\end{array}$ & $\begin{array}{r}\text { Apt, } \\
\text { s/w }\end{array}$ & $\begin{array}{r}\text { Apt, } \\
\text { s/f }\end{array}$ \\
\hline$S_{E B E}, \mathrm{~g}$ & 0.20 & 0.30 & 0.30 & 0.30 & 0.30 & 0.30 & 0.30 & 0.30 \\
\hline$S_{N Z}, \mathrm{~g}$ & 0.05 & 0.15 & 0.25 & 0.15 & 0.15 & 0.15 & 0.15 & 0.15 \\
\hline PFL & $\$ 613,000$ & 4,509 & 547 & 10,468 & 8,769 & 6,378 & 4,851 & 4,957 \\
\hline$m$ & 8.80 & 6.05 & 6.05 & 6.05 & 6.05 & 6.05 & 6.05 & 6.05 \\
\hline$G\left(S_{N Z}\right), \mathrm{yr}^{-1}$ & 0.103 & 0.087 & 0.041 & 0.087 & 0.087 & 0.087 & 0.087 & 0.087 \\
\hline$H, \mathrm{yr}^{-1}$ & 0.0778 & 0.096 & 0.136 & 0.096 & 0.096 & 0.096 & 0.096 & 0.096 \\
\hline Approx EAL & $\$ 47,704$ & 433 & 74 & 1,006 & 843 & 613 & 466 & 476 \\
\hline Exact EAL & $\$ 54,578$ & 614 & 205 & 1,829 & 1,199 & 854 & 522 & 453 \\
\hline \$ error & $(\$ 6,874)$ & (181) & (131) & $(823)$ & $(357)$ & $(241)$ & (56) & 24 \\
\hline$\%$ error & $-13 \%$ & $-29 \%$ & $-64 \%$ & $-45 \%$ & $-30 \%$ & $-28 \%$ & $-11 \%$ & $5 \%$ \\
\hline
\end{tabular}

Table 1 shows that the approximation produces results that are in many cases very close, and in some merely in the correct order of magnitude. However, even an $E A L$ that underestimates the "exact" answer by $64 \%$ can be informative in the absence of any other information. Also, some of this error might be the result of the fairly gross intensity increments of $0.1 \mathrm{~g}$; in future work, we will reduce these increments at lower shaking levels.

\section{CONCLUSIONS}

This paper has introduced a seismic economic performance parameter called probable frequent loss $(P F L)$, defined as the expected value of loss conditioned on the occurrence of ground shaking severity with $10 \%$ exceedance probability in 5 years. This level of seismic excitation is more closely associated with the bulk of economic losses than is the more commonly-used probable maximum loss (PML), which tends to reflect losses in a rare, large event. Also, PFL better reflects a property investor's typical planning period, and thus would be more meaningful as a reasonable upperbound loss. Because of its similarity to $P M L, P F L$ should be readily understood by engineers and investors, and could be calculated during the due-diligence phase of the 
property bidding process. It is more likely to reflect pre-yield response, which means that it might be calculated to a good approximation by using elastic spectral analysis. This will be examined in future work. Expected annualized loss (EAL) is proportional to $P F L$ through a hazard parameter $H$ that can be tabulated. $E A L$ can in turn be used in the calculation of expected seismic life-cycle costs that may be used in a financial analysis to reflect properly the influence of the seismic risk on property valuation, and thus make seismic risk more of a property market parameter.

\section{ACKNOWLEDGMENTS}

Portions of this research were supported by the George W. Housner Senior Research Fellowship, Phase IV of the CUREE-Kajima Joint Research Program and the CUREE-Caltech Woodframe Project. Thanks also to David L. McCormick, Steven K. Harris, Ron Mayes, Greg Flynn, and Jeff Berger, who provided advice on portions of the research. Their contributions are gratefully acknowledged.

\section{APPENDIX I. REFERENCES}

American Society for Testing and Materials (ASTM). (1999). E 2026-99 Standard Guide for the Estimation of Building Damageability in Earthquakes, West Conshohocken, PA, 24 pp.

Applied Technology Council. (1985). ATC-13: Earthquake Damage Evaluation Data for California, Redwood City, CA, 492 pp.

Beck, J.L., Kiremidjian, A.S., Wilkie, S., Mason, A., Salmon, T., Goltz, J., Olson, R., Workman, J., Irfanoglu, A., and Porter, K. (1999). Decision Support Tools for Earthquake Recovery of Businesses, Final Report, Consortium of Universities for Earthquake Engineering Research, Richmond, CA

Beck, J.L., Porter, K.A., Shaikhutdinov, R.V., Au, S.K., Moroi, T., Tsukada, Y., and Masuda, M. (2002). Impact of Seismic Risk on Lifetime Property Values, Final Report, Consortium of Universities for Research in Earthquake Engineering, Richmond, CA, http://resolver.caltech.edu/caltechEERL:2002.EERL-2002-04

International Code Council (ICC). (2000). International Building Code 2000, International Conference of Building Officials, Whittier, CA, 756 pp.

Leyendecker, E.V. (2001). Uniform Hazard Response Spectra and Seismic Hazard Curves for the United States, U.S. Geological Survey, Denver, CO

National Institute of Building Sciences (NIBS) and Federal Emergency Management Agency (FEMA). (1999a). HAZUS-99 Software, FEMA, Washington, DC, www.fema.gov/hazus/

Porter, K.A. (2000). Assembly-Based Vulnerability of Buildings and its Uses in Seismic Performance Evaluation and Risk-Management Decision-Making. Stanford University Doctoral Dissertation, pub. 99-95274, ProQuest Co., Ann Arbor, MI, 196 pp., http://wwwlib.umi.com/dissertations/preview/9995274 
Porter, K.A., Beck, J.L., Seligson, H.A., Scawthorn, C.R., Tobin, L.T., and Boyd, T. (2002a). Improving Loss Estimation for Woodframe Buildings. Richmond, CA: Consortium of Universities for Research in Earthquake Engineering, 136 pp., http://resolver.library.caltech.edu/caltechEERL:2002.EERL-2002-01 http://resolver.library.caltech.edu/caltechEERL:2002.EERL-2002-02

Porter, K.A., Beck, J.L., and Shaikhutdinov, R.V. (2002b). "Sensitivity of building loss estimates to major uncertain variables," Earthquake Spectra, 18 (4), 719-743, http://keithp.caltech.edu/publications.htm

Porter, K.A., Kiremidjian, A.S. and LeGrue, J.S. (2001). "Assembly-based vulnerability of buildings and its use in performance evaluation," Earthquake Spectra, 17 (2), 291-312.

Risk Engineering. (2002). ST-RISK Software, Version 3.2, www.st-risk.com

Zadeh, M.M. (2000). "Understanding risk management," Financial Management of Earthquake Risk, Oakland CA: Earthquake Engineering Research Institute, 1-14

\section{APPENDIX II. NOTATION}

$a=$ slope of a linear approximation of the seismic vulnerability function

$b=y$-intercept of a linear approximation of the hazard function in the log-linear domain

$E A L=$ expected annualized loss

$E B E=$ economic-basis earthquake, an event with $10 \%$ exceedance probability in 5 years

$g(S)=$ average annual frequency of experiencing severity $S$ per unit $S$

$G(S)=$ mean annual frequency of exceeding shaking $S$

$H=$ hazard parameter, the constant of proportionality between $E A L$ and PFL

$m=$ slope magnitude of the $\log$ hazard function: $d(\ln (G(S))) / d S$, evaluated at $S_{E B E}$

$P F L=$ probable frequent loss, mean loss conditioned on the occurrence of $\mathrm{S}_{\mathrm{EBE}}$

$P M L=$ probable maximum loss

$S=$ earthquake severity (e.g., spectral acceleration)

$S_{a}=5 \%$-damped elastic spectral acceleration response

$S_{E B E}=$ shaking severity from the $E B E$

$S_{N Z}=$ threshold of shaking severity causing significant economic loss

$V=$ value exposed to loss (e.g., replacement cost of the building)

$y(S)=$ mean seismic vulnerability, i.e., expected loss given shaking severity $S$, expressed as a fraction of $V$ 